\title{
BIOCONTROL OF FUSARIUM OXYSPORUM IN UNSTERILIZED SOIL BY NOVEL STREPTOMYCES CACAOI SUBSP CACAOI [M20]
}

\author{
T. JANAKI \\ Department of Botany, K. M. Centre for P. G. Studies (Autonomous), Puducherry-8, India \\ Email: janakishaila@gmail.com
}

Received: 13 Dec 2016 Revised and Accepted: 09 Jan 2017

\begin{abstract}
Objective: To find bio fungicide from mangrove actinomycetes for controlling seed and soil borne pathogen-Fusarium oxysporum.

Methods: A total of 25 actinomycetes were isolated by pour plate method. These were screened for fungicidal activity by agar plug method. The isolate M20 was characterised further for identification. The phytotoxicity study was done; biocontrol of Fusarium oxysporum with $10 \%$ culture filtrate was done using food poisoning technique. Volatile toxicity of isolate M20 was studied by inverted plate technique. The methanolic crude extract was subjected for UV-Vis spectral analysis for identifying the group of compound present.

Results: The isolated M20 found to be better in antifungal activity. 10\% culture filtrate actively inhibited the growth of Fusarium oxysporum (77.7\%), 10\% culture filtrate was taken as a standard concentration for biocontrol of Fusarium oxysporum using green gram as the test plants. The $15^{\text {th }}$-day green gram plants under treatment with the antagonist $(A)$, antagonist + pathogen $(A+P)$, antagonist+pathogen + rhizobium $(A+P+R)$ yielded high biomass and better growth. The disease development by the pathogen in green gram was controlled by the antagonist. The compounds (pyrimidine nucleosides-neutral and acidic polyoxins $(230 \mathrm{~nm}),(270-290 \mathrm{~nm})$ and heptaene antifungal antibiotics (406-417 $\mathrm{nm})$ ) are preliminarily confirmed from the methanolic crude extract of the isolate M20-Streptomyces cacaoi subsp cacaoi.
\end{abstract}

Conclusion: Since the isolate M20 controlled the growth and disease causing potentiality of Fusarium oxysporum, it can be effectively used to control seed and soil borne diseases that are caused by Fusarium oxysporum.

Keywords: Avicennia marina, Phytotoxicity, Antifungal activity, Fusarium oxysporum, Biocontrol, Bio-fungicide, Mangrove actinomycetes

(C) 2016 The Authors. Published by Innovare Academic Sciences Pvt Ltd. This is an open access article under the CC BY license (http://creativecommons.org/licenses/by/4. 0/) DOI: http://dx.doi.org/10.22159/ijpps.2017v9i3.16579

\section{INTRODUCTION}

Many species of Fusarium occur regularly causing considerable crop losses and produce several mycotoxins in crops that are grown under varied agro-climatic conditions in India [1, 2], and the members of genus Fusarium show increased genetic variability, therefore increases the difficulties encountered in the development of resistant host genotypes. Fusarium oxysporum is a ubiquitous soil borne plant pathogen with more than 150 host-specific forms $[3,4]$. Fusarium wilt is a common vascular wilt fungal disease caused by the pathogen called Fusarium oxysporum [5]. It is most widely found in worldwide [6]. It is a common soil pathogen and saprophyte that feeds on dead and decaying organic matter. It survives in the soil debris as a mycelium and all spore types but is most commonly recovered from the soil as chlamydospores [5]. It affects a wide variety of hosts of any age. It generally produces symptoms such as wilting, chlorosis, necrosis, premature leaf drop, browning of the vascular system, stunting, and damping-off and vascular wilt. Crop losses in leguminous members by species of Fusarium are being investigated extensively by the plant pathologists. Though some bacteria, fungi and terrestrial actinomycetes [7] have been implicated as biocontrol agents, work on the antagonistic actinomycetes from mangrove soil is comparatively very less. Therefore an attempt was made to use mangrove actinomycetes as a biocontrol agent in controlling soil-borne disease caused by Fusarium oxysporum.

\section{Mangrove actinomycetes}

Mangroves provide a unique ecological niche to different microbes which play various roles in nutrient recycling as well as various environmental activities. The fertility of mangrove water results from the decomposition of organic matter and recycling of nutrients by microorganisms [8-10]. Due to the presence of a rich source of nutrients in mangrove soil, mangroves are called as a homeland for microbes. Microbial counts are high during monsoon months when nutrients are brought in by freshwater ingression. These types of morphological adaptations in mangroves to live in fluctuated soil $\mathrm{pH}$, temperature, soil nutrients and root exudates in the rhizosphere enhances to spread the microbial diversity including actinomycetes. The secondary metabolites produced by the mangrove oriented actinomycetes are entirely different from terrestrial actinomycetes. Mangrove ecosystem is the most productive ecosystem diversified with a variety of microbes. Analysis of microbial bioactivity from these ecosystems will help in isolating and identifying new and potential microbes having high specificity for various applications. Isolation of actinomycetes from unique, unexplored natural habitats is of interest to avoid re-isolation of strains that produce known bioactive metabolites. Neglected habitats like mangroves are proving to be a good source of novel actinomycetes and bioactive compounds. Some reports related to the work stating that mangrove soil is a major source of actinomycetes [11], mangrove actinomycetes are very good in antibacterial and antifungal activity in controlling pathogenic bacteria and fungi [12]. Mangrove actinomycetes are major sources for finding out bio-fungicide for plant welfare [13]. So, these can be effectively used to prepare bio fungicides and these can act as an alternative source for the problems caused by indiscriminate use of chemical fungicides in the living ecosystem that led the adverse effects of bio-magnification and bioaccumulation. It is an approach to find bio fungicide from mangrove actinomycetes for controlling seed and soil borne pathogen-Fusarium oxysporum.

\section{MATERIALS AND METHODS}

\section{Isolation of mangrove actinomycetes}

Avicennia marina (Forsk). Vierh-(Avicenniaceae) are dominant mangrove plants in Ariyankuppam backwater area, Puducherry. The soil sample was collected near the root region of Avicennia marina. The soil sample was subjected to dry heat $\left(70{ }^{\circ} \mathrm{C}\right.$ for $\left.15 \mathrm{~min}\right)$ [14] pretreatment. After pretreatment, one gram soil was mixed and 
serially diluted. $0.1 \mathrm{ml}$ of last two dilutions $\left(10^{-5}\right.$ and $\left.10^{-6}\right)$ was inoculated by pour plate method using starch casein agar (SCA) [15] supplemented with fluconazole $80 \mu \mathrm{g} / \mathrm{ml}$ and nalidixlic acid $75 \mu \mathrm{g} / \mathrm{ml}$. Plates were incubated at $28 \pm 2{ }^{\circ} \mathrm{C}$ for up to $30 \mathrm{~d}$. Selected colonies were maintained in yeast malt extract agar (YMEA) slants.

\section{Chemicals and culture media used}

Starch casein agar (SCA), yeast malt extract agar (YMEA), potato dextrose agar (PDA), potato dextrose broth (PDB), nutrient glucose agar (NGA), fluconazole, nalidixlic acid, 16sRNA sequencing kit (Zeal), methanol were purchased from Himedia, India.

\section{Test organism used in this study and its preparation}

The fungus used in this study was Fusarium oxysporum (MTCC-1755) procured from MTCC, Chandigarh. Test fungus was maintained in Potato dextrose broth (PDB) and in Potato dextrose agar (PDA) slants, pH-6. This was stored in a refrigerator at $4{ }^{\circ} \mathrm{C}$ for future use. 5-7 d old fungal liquid culture and plate culture was used for the antifungal study.

\section{In-vitro screening for antifungal activity}

Primary screening by agar plug method was studied [16], only one isolate M20 was selected (based on its antifungal activity) for biocontrol studies to control the target pathogen-Fusarium oxysporum.

\section{Biochemical and molecular characterization of isolate M20}

Production of extracellular enzyme chitinase [17] was tested because it is necessary to degrade the cell wall of fungal pathogens. Nitrate reduction activity [18] Phosphatase activity [19] of isolate M20 also tested for its plant growth promoting potential. For the 16sRNA sequencing analysis of isolate M20, the purified PCR products of approximately 1,400bp were sequenced by using 2 universal primers: 518F 5'CCAGCAGCCGCGGTAATACG 3', 800R 5' TACCAGGGTATCTAATCC 3'. The isolate M20 was identified, and a phylogenetic tree was constructed.

\section{Effect of culture filtrate of isolate M20 on radial growth of Fusarium oxysporum}

Food poisoning technique [20] was followed to study the effect of culture filtrate of M20 on radial growth of Fusarium oxysporum, 10 $\mathrm{ml}$ culture filtrate was added to $90 \mathrm{ml}$ of molten potato dextrose agar (pH 6) to get a final concentration of $10 \%$. Now the $100 \mathrm{ml}$ potato dextrose agar medium was ready to serve 5 sterilised Petri plates with dia $90 \mathrm{~mm}$. PDA petri plates without $10 \%$ culture filtrate were kept as a control for the test fungal pathogenFusarium oxysporum. All the plates were then inoculated in the centre with $8 \mathrm{~mm}$ dia. mycelial plug cut from actively growing plate culture of Fusarium oxysporum.

All the plates were incubated under room temperature $28 \pm 2{ }^{\circ} \mathrm{C}$ for 4-5 d. The growth of the fungal pathogen in treated plates was measured when the growth of the organism in control plate was full. The percentage inhibition in mycelial growth was calculated using the standard equation given below.

$$
=\text { Control-Treatment }(10 \%) / \text { Control } \times 100
$$

\section{Test for volatile toxicity}

Production of volatile toxic material by the isolate of the M20 was assessed by inverted plate technique [21]. Six modified nutrient glucose agar (NGA) plates ( $\mathrm{pH}$ 7.5) were inoculated with the spore suspension of isolate M20 and incubated for $10 \mathrm{~d}$. After $10 \mathrm{~d}$, another set of six PDA petri plates were inoculated centre with a mycelial disc of the test pathogen Fusarium oxysporum.

Then the base of the plates containing the test fungi was placed upside down on the basal plates containing the growth of isolate M20. Plates were sealed with adhesive tape to prevent the escape of volatile factors. The sealed plates were incubated at room temperature along with a suitable control for $5 \mathrm{~d}$. The growth measurements were made after $5 \mathrm{~d}$. In another set of Petri plates, PDA amended with culture filtrate $10 \%$ of isolate M20 was used to test the combined effect of volatile as well as non-volatile antibiotics on the mycelial growth of the pathogen.
Phytotoxicity of the culture filtrate of M20 on seed germination and seedling growth of green gram

Effect of culture filtrate on Vigna radiata's [(L.) (Mung bean) variety Co-8, TNAU] seed germination, early seedling growth was tested. The emergence of radicle was taken as the criteria for germination. The number of germinated seeds was counted after $48 \mathrm{~h}$ and percent germination was calculated using the formula.

$=$ Number of seeds germinated/Total number of seeds sown $\mathrm{x} 100$

Since seed germination was beneficial at $10 \%$, relative to other concentration of culture filtrate and control. The seeds treated with $10 \%$ culture filtrate were transferred to plastic cups (10 seeds/cup) filled with mixture soil (garden soil: sand: compost-2: 1: 1) and watered daily and observed for post-treatment changes.

The seedlings were harvested $15 \mathrm{~d}$ after sowing. The plants were carefully uprooted and the roots were washed in tap water and blotter dried to remove excess moisture. The root, shoot length, fresh weights were recorded.

\section{Biocontrol of Fusarium oxysporum in unsterilized soil by the isolate M20}

The ability of the isolate M20 to suppress disease development in unsterilized soil was tested in plastic cup culture using F. oxysporum as the target pathogen.

\section{(a) Preparation of the actinomycete M20 inoculum}

Modified nutrient glucose broth $(1000 \mathrm{ml}) \mathrm{pH} 7.5$, was sterilised, cooled and inoculated with $50 \mathrm{ml}$ spore suspension of isolate M20. The inoculated flask was incubated at the static condition at $30^{\circ} \mathrm{C}$ for $12 \mathrm{~d}$. The mycelial mass $25 \mathrm{~g}$ was collected by filtration, homogenised and agitated for $5 \mathrm{~min}$. The healthy, surface sterilised seeds were soaked in homogenised mycelial mass for $5 \mathrm{~h}$. This suspension was used for seed and soil treatment.

\section{(b) Preparation of the pathogen inoculum}

Potato dextrose broth $(100 \mathrm{ml})$ was inoculated with Fusarium oxysporum and incubated under room temperature $28 \pm 2{ }^{\circ} \mathrm{C}$ for $5 \mathrm{~d}$. The mycelial mass was collected, homogenised and agitated with $15 \mathrm{ml}$ of sterile distilled water. The healthy, surface sterilised seeds were soaked in homogenised mycelial mass for $5 \mathrm{~h}$ and allowed to multiply.

\section{(c) Rhizobium mixture}

Rhizobium mixture was prepared by using commercially available rhizobium $5 \mathrm{ml}$ with $50 \mathrm{ml}$ sterilised distilled water.

\section{(d) Preparation of soil mixture}

Soil mixture was prepared by mixing in the proportion of 2:1:1 and used for the experiment. Garden red soil: sand: compost (2: 1: 1) mixture was used for plastic cup experiment.

\section{(e) Treatments used}

A total of eight treatments were used to assess biocontrol potential of the isolate M20. The treatments were as follows; 1 . Control (only soil mixture), 2. Antagonist (mycelial mass), 3. Rhizobium, 4. The pathogen, 5. Antagonist (mycelial mass)+rhizobium, 6. Antagonist (mycelial mass)+pathogen, 7. Rhizobium+pathogen, 8. Antagonist (mycelial mass)+rhizobium+pathogen

\section{(f) Soil treatment}

Antagonist's spore suspension $(30 \mathrm{ml})$ was added in $250 \mathrm{ml}$ sterilised distilled water and this was added with three kilograms of the soil mix. The treated soil was filled in eight $10 \mathrm{~cm}$ plastic cups at the rate of $400 \mathrm{~g} / \mathrm{cup}$. The treatments where soil inoculation of the antagonist was not required the soil mix was directly filled in required number of cups.

\section{(g) Seed treatment}

The surface sterilized (required number of) healthy seeds was soaked in $25 \mathrm{ml}$ of the antagonist mycelial suspension for $5 \mathrm{~h}$ and 
shade dried for $20 \mathrm{~min}$. Where seed treatment was not required, the untreated seeds were used.

The seeds were placed one inch below the soil surface in cups. All the treatments were seen in triplicates. The cups were watered regularly to maintain $60 \%$ water-holding capacity of the soil and maintained under outdoor conditions for $15 \mathrm{~d}$. Five days after sowing germination counts were made in all treatments. At $15 \mathrm{~d}$, the seedlings from one cup from each treatment were removed, washed in tap water and used for root, shoot length and fresh weight determination.

Ultra violet-visible spectral analyses of methanol crude extract of isolate M20

UV-Visible spectral analysis of methanol crude extract of isolate M20 was carried out by using Hitachi U-2010 Spectrophotometer, Wavelength Range: $200 \mathrm{~nm}$ to $800 \mathrm{~nm}$ to know the group of the compounds responsible for suppressing the disease-causing potentiality of Fusarium oxysporum.

\section{RESULTS}

\section{Isolation and screening of actinomycetes}

The $\mathrm{pH}$ of mangrove soil sample collected from Avicennia marina was 7.5. Totally 25 actinomycetes were isolated from a soil sample of Avicennia marina by dry heat $\left(70{ }^{\circ} \mathrm{C}\right.$ for $\left.15 \mathrm{~min}\right)$ pretreatment method. Dry heat method yielded active actinomycetes for antifungal activity. Out of 25 actinomycetes, the M20 has shown very good antifungal activity towards the test pathogen. So, it was characterised further for identification.

\section{Biochemical and molecular characterization of M20}

The isolate was chitinase, phosphatase positive. A positive result was observed in nitrate reduction activity. The 16S rRNA gene sequence was submitted to GeneBank with the accession No. KP872910. The isolate M20 branched along with Streptomyces cacaoi subsp cacaoi (NRBC 12748(T)-AB184115) in the analysis.

Neighbour-joining tree based on $16 \mathrm{~S}$ rRNA sequence showing the phylogenetic relationship between the isolate M20 and other closely related species of the genus Streptomyces

Effect of culture filtrate of M20 of radial growth of Fusarium oxysporum

Control of phytopathogenic fungi-Fusarium oxysporum was initially tested under in vitro condition using $10 \%$ culture filtrate of isolate M20. Inhibition in radial growth of test fungi was observed and noted the inhibition percentage as Fusarium oxysporum $77.7 \%$ (Plate 1 ).

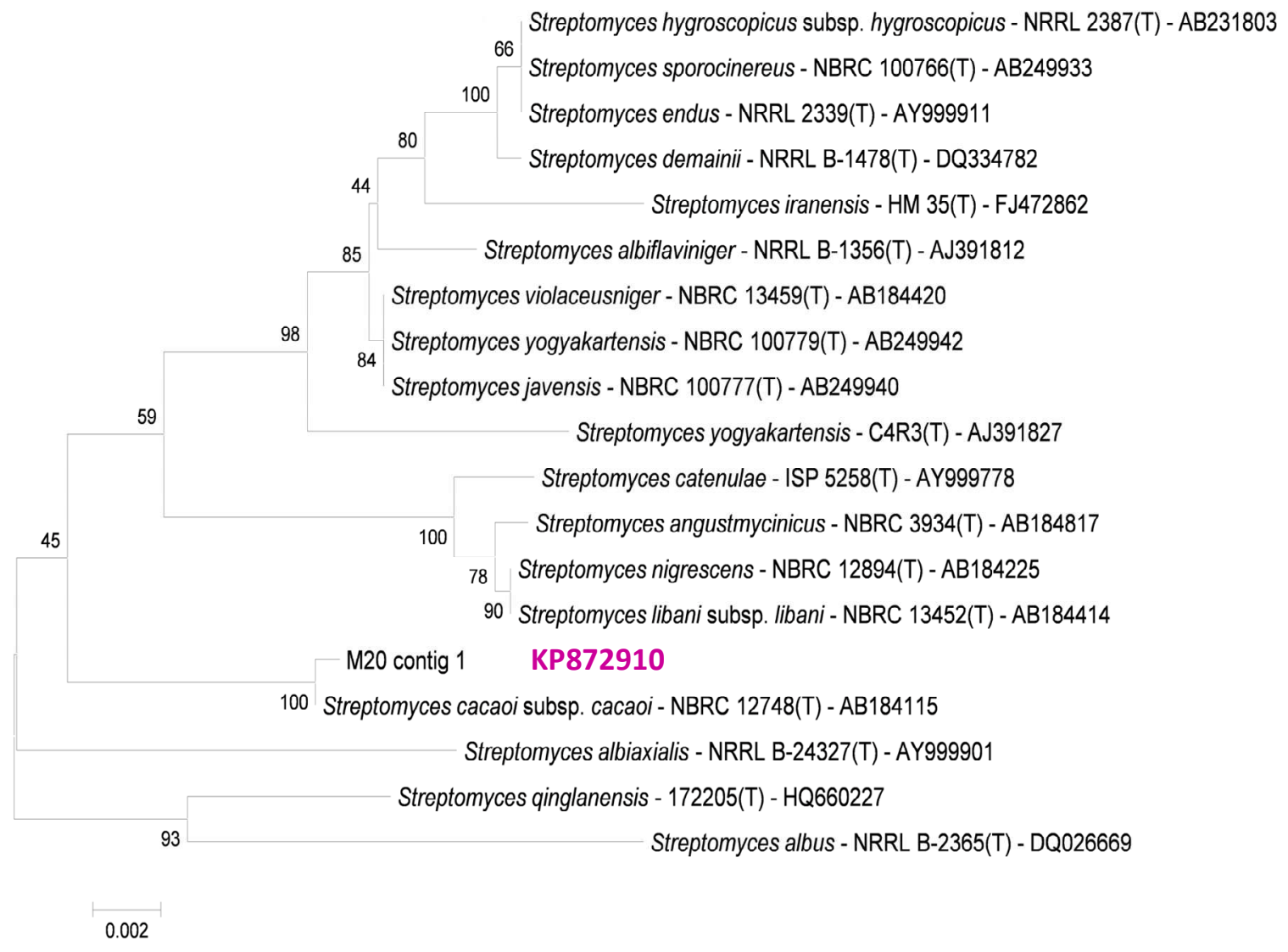

Fig. 1: Phylogenetic tree based on the 16S rRNA sequence homology of M20

Table 1: Effect of culture filtrate of M20 of radial growth of Fusarium oxysporum

\begin{tabular}{llll}
\hline S. No. & Fungi tested & $\mathbf{1 0 \%}$ Culture filtrate & \\
\cline { 3 - 4 } & & Growth in $\mathbf{~ m m}$ & Inhibition in $\mathbf{~ m m}$ \\
\hline 1 & Fusarium oxysporum & $20 \pm 0.2$ & $70 \pm 0.3$ \\
\hline
\end{tabular}

(The data is presented as mean \pm value standard deviation of three replicates $(n=3)$ )

It was evidenced that the $10 \%$ culture filtrate had effectively controlled the Fusarium oxysporum and also noted that the inhibition in radial growth of fungi tested for the activity was stable up to $10-15 \mathrm{~d}$. 


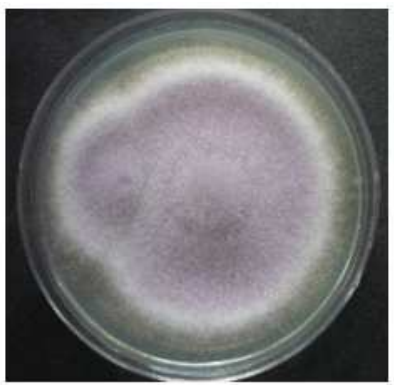

Control

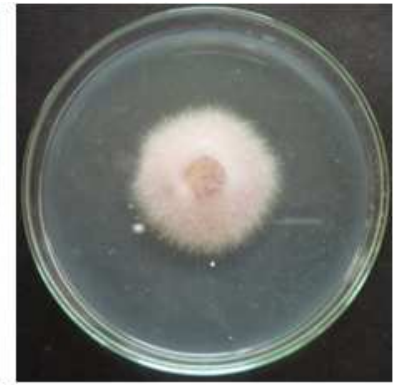

$10 \%$ C.F
Plate 1: Effect of culture filtrate (10\%) on Fusarium oxysporum

\section{Volatile toxicity of the M20}

It was evidenced that the isolate M20 produced musty odour. The volatile compounds produced by the isolate M20 was tested with $F$. oxysporum. It was noticed that the presence of volatile compounds adversely affected the growth and mycelial mass of fungi as $77.7 \%$. The combination of volatile toxicity of $\mathrm{M} 20+10 \%$ culture filtrate enhanced the inhibition of $F$. oxysporum as $88.8 \%$ (Plate 2). The effectiveness of volatile compounds with non-volatile antibiotic compounds on the mycelial growth of test pathogen proved the suppressing capacity of isolate M20.

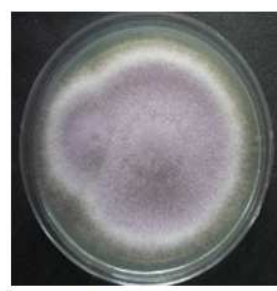

1. Control

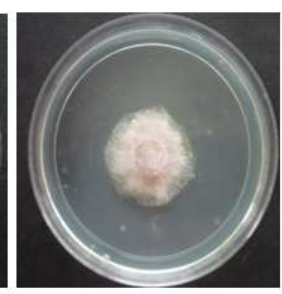

2. Volatile toxicity of $\mathrm{M} 20$ on F.oxysporum

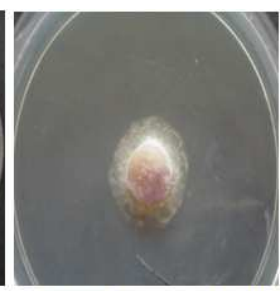

3. Volatile toxicity of $\mathrm{M} 20+$ $10 \%$ C.F on F.oxysporum
Plate 2: Volatile toxicity of the M20 on F. oxysporum
Phytotoxicity of the culture filtrate of M20 on seed germination and seedling growth of green gram

Phytotoxicity of the culture filtrate of M20 at the concentrations of $10 \%, 25 \%, 50 \%, 75 \%$ and $100 \%$ on seed germination and seedling growth of green gram was tested. It was found that, only $10 \%$ culture filtrate supported for seed germination as in the control plate. The seed germination was delayed from the concentration $25 \%$ to $75 \%$. Growth from the seeds was completely arrested at the concentration $100 \%$. The isolate M20 was used as the biocontrol agent in checking the disease-causing potentiality of pathogenFusarium oxysporum in the soil.

Biocontrol of Fusarium oxysporum in unsterilized soil by the isolate M20

It was noticed that the germination of green gram seeds in control was $100 \%$, followed by antagonist (A) was $92 \%$, antagonist rhizobium $(A+R)$ was $90 \%$, this combination with pathogen $(A+R+P)$ was $94 \%$, rhizobium $(\mathrm{R})$ was $80 \%$, pathogen with rhizobium $(\mathrm{P}+\mathrm{R})$ was $74 \%$, $\mathrm{A}+\mathrm{P}$ was $88 \%$ and pathogen $(\mathrm{P})$ was $52 \%$.

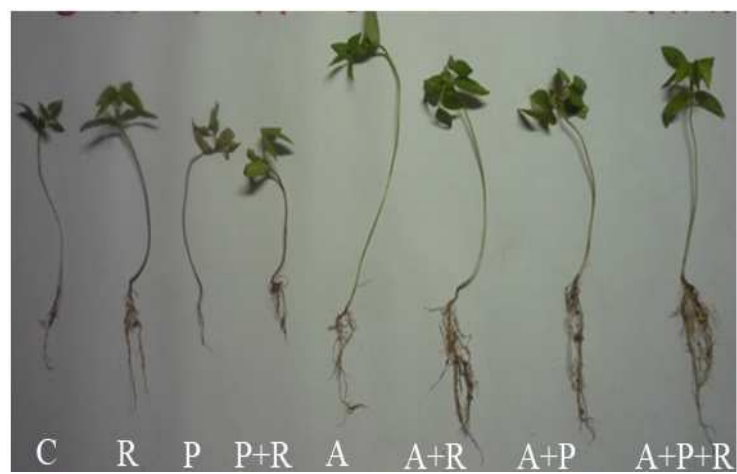

Plate 3: Biocontrol of Fusarium oxysporum in unsterilized soil by the isolate M20, C-control; R-rhizobium; P-pathogen; P+Rpathogen+rhizobium; A-antagonist A+R-antagonist+rhizobium; $\mathrm{A}+\mathrm{P}$-antagonist+pathogen; $\mathrm{A}+\mathrm{P}+\mathrm{R}$ antagonist+pathogen+rhizobium

Table 2: Biocontrol of Fusarium oxysporum in unsterilized soil by the isolate M20

\begin{tabular}{|c|c|c|c|c|c|c|c|}
\hline \multirow[t]{2}{*}{ Treatment } & \multirow{2}{*}{$\begin{array}{l}\text { \% Seed } \\
\text { germination }\end{array}$} & \multicolumn{2}{|c|}{ Length cm/plant } & \multirow{2}{*}{$\begin{array}{l}\text { Total length } \\
\text { cm/plant }\end{array}$} & \multicolumn{2}{|c|}{ Fresh weight mg/plant } & \multirow[t]{2}{*}{ Total weight (mg) } \\
\hline & & Shoot & Root & & Shoot & Root & \\
\hline $\mathrm{C}$ & 100 & $14.5 \pm 0.2$ & $6.5 \pm 0.2$ & $21 \pm 0.2$ & $602 \pm 0.2$ & $86 \pm 0.2$ & $688 \pm 0.2$ \\
\hline $\mathrm{R}$ & 80 & $14.5 \pm 0.2$ & $10 \pm 0.2$ & $24.5 \pm 0.2$ & $385.3 \pm 0.2$ & $91.3 \pm 0.2$ & $476.6 \pm 0.2$ \\
\hline $\mathrm{P}$ & 52 & $11.5 \pm 0.2$ & $5 \pm 0.2$ & $16.5 \pm 0.2$ & $51.68 \pm 0.2$ & $20.3 \pm 0.2$ & $71.98 \pm 0.2$ \\
\hline$P+R$ & 74 & $12 \pm 0.2$ & $6 \pm 0.2$ & $18 \pm 0.2$ & $650 \pm 0.2$ & $154 \pm 0.2$ & $804 \pm 0.2$ \\
\hline A & 92 & $21.2 \pm 0.2$ & $10 \pm 0.2$ & $31.2 \pm 0.2$ & $624.6 \pm 0.2$ & $92.3 \pm 0.2$ & $716.9 \pm 0.2$ \\
\hline$A+R$ & 90 & $16 \pm 0.2$ & $13 \pm 0.2$ & $29 \pm 0.2$ & $575 \pm 0.2$ & $268 \pm 0.2$ & $843 \pm 0.2$ \\
\hline$A+P$ & 88 & $14.5 \pm 0.2$ & $11.5 \pm 0.2$ & $26 \pm 0.2$ & $740 \pm 0.2$ & $245 \pm 0.2$ & $985 \pm 0.2$ \\
\hline $\mathrm{A}+\mathrm{P}+\mathrm{R}$ & 94 & $14.5 \pm 0.2$ & $13.5 \pm 0.2$ & $28 \pm 0.2$ & $743.2 \pm 0.2$ & $346.3 \pm 0.2$ & $1089.5 \pm 0.2$ \\
\hline
\end{tabular}

(The data is presented as mean \pm value standard deviation of three replicates $(n=3)$ )

It was observed that the presence of secondary leaves in all the treatment except in pathogen-inoculated. The rhizobium inoculated seedlings had thick shoot stems with 10 secondary roots. Leaf size was bigger in all the treated seedlings except in control. It was observed that the presence of secondary leaves in all the treatment except in pathogen-inoculated. The rhizobium inoculated seedlings had thick shoot stems with 10 secondary roots. Leaf size was bigger in all the treated seedlings except in control. The leaves were pale green followed by necrosis, the stem is slender, short and root was thinner with very less secondary roots in pathogen treated seedlings, finally there was complete dryness of seedlings was observed (Plate 3). The stem length was longer in antagonist (A) treated seedlings with 12 secondary roots. The combination $\mathrm{A}+\mathrm{P}+\mathrm{R}$ influenced the root length very well with 15 secondary roots. The length and fresh weight of shoot and root of seedlings from the A+P treatment were found to be better followed by $A+R$ than compared to seedlings in other treatments except in $A+P+R$ treatment (table $2)$. The $A+P+R$ treated plants produced young tertiary leaves and very long main root with 20 secondary roots with the tertiary formation roots. The fresh weight of seedlings from the treatment $\mathrm{A}+\mathrm{P}+\mathrm{R}$ was higher than compared to seedlings in other treatments.

It was found that the combination of rhizobium with the antagonist (Isolate M20) effectively suppressed and controlled the growth of Fusarium oxysporum and also this combination influenced the growth of seedlings higher than in the control. Biocontrol of Fusarium oxysporum was possible in soil with the antagonist (isolate M20) and the PGPR-Rhizobium. 


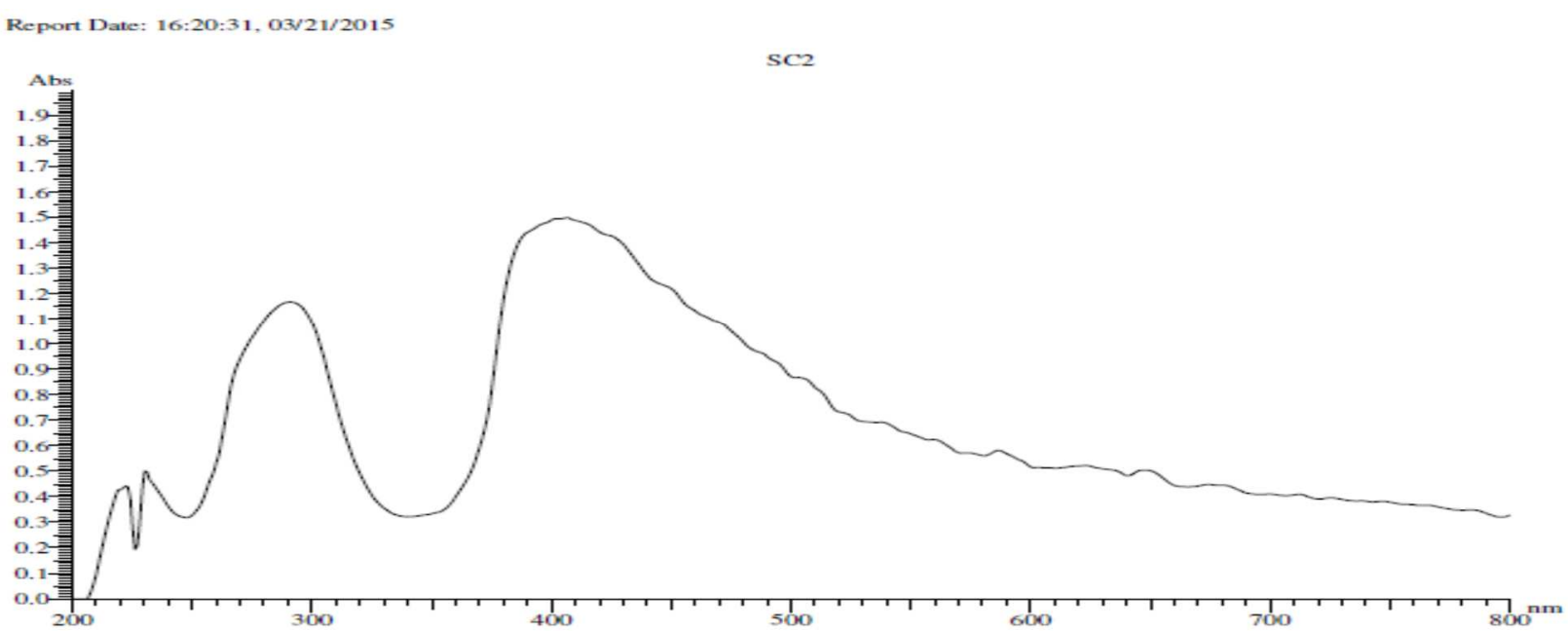

Fig. 2: Ultra violet-visible spectrum of methanol crude extract of isolate M20

UV-Vis spectral analysis of methanol crude extract of M20 has shown 4 peaks and maximum absorbance at $406 \mathrm{~nm}$, absorbance height of the group of compound was 1.500 and it occupied the area was 321.996 (Abs*nm) followed by $291 \mathrm{~nm}$, absorbance height of the group of compound was 1.169 and it occupied the area was 69.068 (Abs*nm), $230 \mathrm{~nm}$ absorbance height of the group of compound was 0.501 and it occupied the area was 8.194 (Abs*nm)and $222 \mathrm{~nm}$ absorbance height of the group of compound was 0.442 and it occupied the area was $5.410\left(\mathrm{Abs}^{*} \mathrm{~nm}\right.$ )

\section{DISCUSSION}

Some of the preliminary tests were done to check the efficiency of the isolate M20 in the field of plant protection. Soil-borne plant diseases are mostly caused by Fusarium oxysporum, so, it was initially checked in the laboratory condition (in-vitro) by food poisoning technique with $10 \%$ culture filtrate of isolate M20. The percentage of inhibition by isolate M20 in radial growth of Fusarium oxysporum was 77.7. Since the radial growth of this fungi effectively inhibited by culture filtrate of isolate M20, this was selected as a pathogen and isolate M20 was selected as an antagonist for biocontrol studies. Actinomycetes are known to produce a series of volatile antimicrobial compounds. The presence of volatile compounds-aromatic pyrimidine alkaloids, aromatic hydrocarbons, phenols, aldehydes and esters may be responsible for volatile toxicity for fungi [22]. Volatile compounds adversely affected the growth and mycelial mass of $F$. oxysporum. The combination of volatile toxicity of $\mathrm{M} 20+10 \%$ culture filtrate was used to check the effectiveness of volatile compounds with non-volatile antibiotic compounds on the mycelial growth of $F$. oxysporum. The combination of volatile toxicity of M20+10\% culture filtrate arrested the growth of $F$. oxysporum $88.8 \%$. Production of volatile antibiotics by the isolate M20 is an added advantage; the volatiles can diffuse through the soil particles rapidly and can inactivate the pathogen farther away from the host plant, non-volatile toxic substance are often adsorbed by the soil and organic matter, inactivated whereas the volatiles are not [22].

The antifungal activity of biocontrol agent is usually evaluated under in vitro conditions, but these tests do not take into account how various environmental factors influence biocontrol agents under agricultural conditions. Same was reported [23]. Therefore a plant test is needed to confirm the effectiveness of biocontrol agent; this was similar [24].

The ideal way to biocontrol soil-borne diseases is to treat the seeds with the bioprotectant before sowing. Since the biocontrol agent is in close contact with the toxin produced by the antagonist should not be toxic to the germination of seeds. Therefore the effect of culture filtrate on green gram seed germination was determined. Phytotoxicity of the culture filtrate of M20 at the concentrations of $10 \%, 25 \%, 50 \%, 75 \%$ and $100 \%$ on seed germination and seedling growth of green gram was tested. It was found that only $10 \%$ culture filtrate supported seed germination. The seed germination was delayed from the concentration $25 \%$ to $75 \%$. Growth from the seeds was completely arrested at $100 \%$ concentration. The culture filtrate of isolate M20 at the concentration $100 \%$ acted as the growth inhibitor. From these, it is clear that high doses of any antifungal compound act as a growth inhibitor. As the $10 \%$ culture filtrate produced a good result in seed germination, this concentration was taken for biocontrol study.

The isolate M20 actively involved in nitrate reduction activity. it converts nitrate into simpler forms, this form of nitrogen would not help the plants to utilize nitrogen source, so there is a need for applying the bioagent that are responsible for nitrogen fixation for improving the plant growth during the biocontrol studies with isolated M20, above that rhizobia are symbionts with leguminous members for nitrogen fixation. The present investigation proved the symbiotic association of isolate M20 with rhizobia, enhanced growth of plants and helps the isolate M20 to suppress the disease-causing potential of the fungal pathogen-Fusarium oxysporum.

It was found that the isolate M20 chitinase and phosphatase positive, from these, it was confirmed that the isolate M20 could be act as not only as bioagent for controlling Fusarium oxysporum, but also act as PGPR in improving plant growth. It was found that the combination of Rhizobium with the antagonist (Isolate M20) also suppressed and controlled the growth of Fusarium oxysporum, and also this combination influenced the growth of seedlings better than in control. Biocontrol of Fusarium oxysporum was possible in soil with the antagonist (isolate M20) and Rhizobium effectively. The compounds (pyrimidine nucleosides-neutral and acidic polyoxins $(230 \mathrm{~nm}),(270-290 \mathrm{~nm})$ and heptaene antifungal antibiotics (406$417 \mathrm{~nm})$ ) are preliminarily confirmed from the methanolic crude extract of the isolate M20-Streptomyces cacaoi subsp cacaoi by the UV-Visible spectral analysis with the help of absorption spectra of reference antibiotics [25].

A new class of natural fungicides Polyoxin B and D as metabolites of Streptomyces cacaoi var. asoensis had been isolated in 1965 [26]. They interfere with the fungal cell wall synthesis by inhibiting chitin synthase (Endo and Misato 1969) [27]. Polyoxin B found application against a number of fungal pathogens in fruits, vegetables and ornamentals. Bio fungicidal compound from Streptomyces cacaoi had been isolated [28]. These are the some of the evidences supported that the isolate M20-Streptomyces cacaoi subsp cacaoi can be effectively used to control the seed and soil borne pathogens as in the form of biocontrol agent and its compounds from culture filtrate as in the form of bio-fungicide. 


\section{CONCLUSION}

The pathogen-Fusarium oxysporum cause a severe loss on the yield of legumes by wilting. To tackle the problem of chemical hazards and resistance in the pathogen, bio fungicides are prepared and used by the microbiologists. Though the bio fungicides from bacteria and fungi are ruled over the agriculture field to control the pathogens, bio fungicide from mangrove actinomycetes are most preferable, because, that can produce safer and novel antibiotics. Mangrove actinomycetes are a very good source for producing bioactive compounds for controlling phytopathogens as in the form both biocontrol agent and as bio-fungicide. The isolate M20-Streptomyces cacaoi subsp cacaoi produced chitinolytic enzymes to degrade chitin cell wall composition of Fusarium oxysporum. The compounds (pyrimidine nucleosides-neutral and acidic Polyoxins $(230 \mathrm{~nm})$, (270-290 nm) and Heptaene antifungal antibiotics (406-417 nm)) from the culture filtrate of isolate M20-Streptomyces cacaoi subsp cacaoi are active in controlling disease potential of the target pathogen-Fusarium oxysporum and enhanced the growth of green gram seedlings better than in the control. So, it can be effectively used in the field of plant protection.

\section{CONFLICT OF INTERESTS}

Declared none

\section{REFERENCES}

1. Ramana MV, Nayaka SC, Balakrishna K, Murali HS, Batra HV. A novel PCR-DNA probe for the detection of fumonisinproducing Fusarium species from major food crops grown in southern India. Mycol 2012:3,164-7.

2. Chandra NS. Prospects of molecular markers in Fusarium species diversity. Appl Microbiol Biotechnol 2011;90:1625-39.

3. Baayen RP. Gene genealogies and AFLP analyses in the $F$. oxysporum complex identify monophyletic and nonmonophyletic formae speciales causing wilt and rot disease. Phytopathology 2000;90:891-900.

4. Asha BB, Chandra Nayaka S, Udayashankar AC, Srinivas C, Niranjana SR. Selection of effective bio-antagonistic bacteria for biological control of tomato wilt caused by Fusarium oxysporum. Biol Scand 2011;6:239-44.

5. Snyder WC, Hansen HN. The species concept in Fusarium. Am J Bot 1940;27:64-7.

6. Agrios, George N. Plant Pathology. 5th ed. Amsterdam: Elsevier Academic; 2005. p. 522

7. Singh C, Parmar RS, Jadon P, Kumar A. Characterization of actinomycetes against phytopathogenic fungi of Glycine Max (L.). Asian J Pharm Clin Res 2016; 9 Suppl 1:216-9.

8. Thongchai $T$, Chanaphat $S$, Wanwikar R, Phutdhawong WS. Antifungal activity of 3-methylcarbazoles from Streptomyces sp. LJK109; an endophyte in Alpinia galangal. J Appl Pharm Sci 2012;2:124-8.

9. Sateesh V, Patil N, Rathod J. Selective isolation and antimicrobial activity of rare actinomycetes from mangrove sediment of Karwar. J Eco bio technol 2011;3:48-53.

10. Silambarasan S, Kumar EP, Murugan T, Saravanan D, Balagurunathan R. Antibacterial and antifungal activities of Actinobacteria isolated from Ratnagiri hills. J Appl Pharm Sci 2012;2:99-103.
11. Dhanasekaran D, Panneerselvam A, Thajuddin N. An antifungal compound: 4' phenyl-1-napthyl-phenyl acetamide from Streptomyces spp. DPTB16. Facta Universitatis Series: Med Biol 2008;15:7-12.

12. Janaki T, Nayak BK, Ganesan T. Antifungal activity of soil actinomycetes from the mangrove Avicennia marina. J Med Plants Studies 2016b;4:5-8.

13. Janaki T. Biocontrol of Rhizoctonia solani by Streptomyces cacaoi subsp cacaoi. M20. World J Pharm Pharm Sci 2016h;5:1516-27.

14. Hayakawa M, Sadaka T, Kayiura T, Nonomura H. New methods for the highly selective isolation Micromonospora and Microbispora. J Fermen Bioeng 1991;72:320-6.

15. Kuster E, Williams ST. Selection of media for isolation of streptomycetes. Nature 1964;202:928-9.

16. Mohanraj D, Bharathi S, Radhakrishnan M, Balagurunathan R. Bioprospecting of actinobacteria from Yelagiri hills with special reference to antibacterial activity. J Chem Pharm Res 2011;3:439-46.

17. Hsu SC, Lockwood JL. Powdered chitin agar as a selective medium for enumeration of actinomycetes in water and soil. Appl Microbiol 1975;29:422-6.

18. Cuppuccino JG, Sherman N. Microbiology a laboratory manual Sixth edition. Pearson Education; 2002. p. 193-343.

19. Pikovaskaya RI. Mobilisation of phosphorus in soil connection with the vital activity of some microbial species. Mikrobiologiya 1984;17:363-70.

20. Grover RK, Moore JD. Toximetric studies of fungicides against brown rot organism Scelerotina fruitycola. Phytopathology 1962;52:876-80.

21. Bruce A, Austin WJ, King B. Control of growth of Lentinus lepideus by volatiles from Trichoderma. Trans Br Mycol Soc 1984;88:503-13.

22. Janaki T, Ganesan T. Biocontrol of Rhizoctonia solani Kuhn using rhizospheric actinomycetes. M. Phil thesis, Aki Nik Book Publication, Delhi, India; 2016.

23. Nobutaka S. Biological control of fungal plant diseases using antagonistic bacteria. J General Plant Pathol 2008;74:450-60.

24. Makoto S. Bacterial control of plant diseases. J Biosci Bioeng 2000;89:515-21.

25. Monisha Khanna, Renu Solanki, Rup lal. Selective isolation of rare actinomycetes producing novel antimicrobial compounds. Int J Adv Biotech Res 2011;2:357-75.

26. Isono K, Junsaku N, Yoshitsugu K, Saburo S. Studies on polyoxins, antifungal antibiotics part I. isolation and characterization of polyoxins A and B. Agric Biol Chem 1965;29:848-54.

27. Endo A, Misato T. Polyoxin D, a compétitive inhibitor of UDP-Nacetylglucosaminyltransferase in Neurospora crassa. Biochem Biophys Res Commun 1969;37:718-22.

28. Gao F, Wu Y, Wang M. An antagonistic actinomycete for suppression of tobacco brown spot. Biocon Sci Technol 2012;22:371-7.

\section{How to cite this article}

- $\quad$ T Janaki. Biocontrol of Fusarium oxysporum in unsterilized soil by novel Streptomyces cacaoi subsp cacaoi [M20]. Int J Pharm Pharm Sci 2017;9(3):78-83. 